\title{
Combination of laser welding with in-mould assembling into a single process
}

\author{
N. Oliveira \\ IPC - Institute for Polymers and Composites, Department of Polymer Engineering, University of Minho, \\ 4800-058 Guimarães, Portugal-id2694@alunos.uminho.pt
}

\author{
A. J. Pontes \\ IPC - Institute for Polymers and Composites, Department of Polymer Engineering, University of Minho, I3N, \\ Institute of Nanostructures, Nanomodelling and Nanofabrication, 4800-058 Guimarães, Portugal- \\ pontes@dep.uminho.pt
}

ABSTRACT: The search of a process capable of produce and assemble complex subsystems in a short period is the goal of any company. In the market it is possible to found several solutions. They go from simple glue to the complexes systems that use moulds, robot and other. These systems are part of a complex assembling line. In these lines are several different processes as welding, plastic and assembling process. This complex structure is costly, and in countries where the labour cost is high. To maintain the cost the companies are obliged to go overseas. The process presented had the objective of reducing the complexity of an assembling line. The reduction of the complexity is achieved through the combination of the in-mould assembly and the laser welding. The in-mould assembly is used to produce in the same mould several components. Laser welding is used to join different polymers. To study the viability of the process I was chosen a case study, in this case, a rear lamp. Firstly, it was modified to this new process, and then each component was studied individually. Finally, all the processes were combined and it was concluded that this process has viability and to make it possible producing a complex subsystem in one process.

Keywords: Laser, transmittance, polymer, in-mould assembly.

\section{INTRODUCTION}

In the present globalized world, any client can buy whichever he wants. Where the previous local competition turned into a global competition, in which the price is the main factor in any decision. Many companies were obliged to go overseas to not lose clients, and to maintain competitive the cost of the product. Other companies followed another path; they started developing new processes that are capable to compete with labour costs of third world countries. One of the industries, where this occurred was the plastic injection mould (Feenstra 1998).

The technology presented in this paper has the objective of increasing the competiveness by reducing the production cycle. This new process combines the in-mould assembling with the laser welding process.

The laser welding is a process that uses different types of lasers to join all known plastics. The welding with this technology can be made directly or by transmission process. The direct process uses mainly the CO2 laser to weld (Troughton 2008). The wavelength emitted by this laser $(10300 \mathrm{~nm})$ is absorbed by all plastics. On contrary in the transmission welding process solid lasers are used to weld. The main solid lasers used are the diode (800 and $1100 \mathrm{~nm}$ ). These lasers emit a beam that doesn't interact with the plastic materials. Despite of this disadvantage, it is possible to join two plastics materials. The transmission welding needs two materials, one that is transparent to the laser and another that absorbs the beam. In this process the two materials are overlapped (Fig. 1), with the material transparent to the laser in the top and the other material that is capable to absorb the laser at the bottom. To overcome the transparency of the materials it is mandatory to use additives.

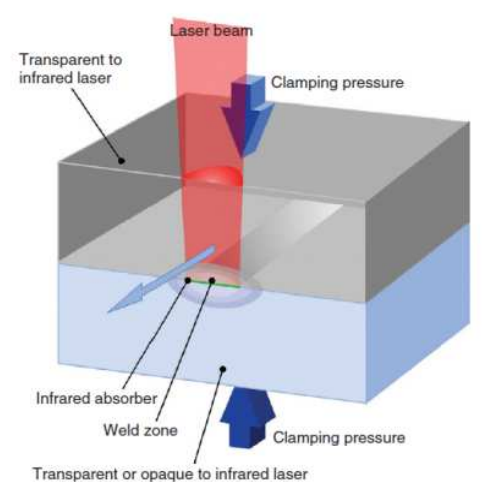

Figure 5 Laser welding by transmission (Troughton 2008)

Another technology that was used in this process was the in-mould assembling (Fig. 2). This process is commonly used in plastics injection moulding, to produce and assembling two or more components 
(Cunha \& Pontes 2009). This process is based on assembling different plastics components inside of the same mould. The increment on the complexity of the designs of the cars pushed the companies to develop new assembling processes capable of in a fast way producing complex subsystem. The research for new processes has obliged companies to develop new moulds capable of assembling entire subsystems. In this case, it is possible to find in the market moulds with rotary cavities, complex movements and with multiple partition lines capable of changing their configuration during the injection process. The more common technique in in-mould assembling is the use of robots or similar solutions, to exchange the different parts between the cavities (Goodship \& Love 2002; Cunha \& Pontes 2009).

As an assembling process it presents the following advantages:

- Production of the product occurs inside of mould and erases the needs of stock between processes.

- This process avoids the needs of utilization of more than one mould or other tools, thus diminishing the work and the space necessary.

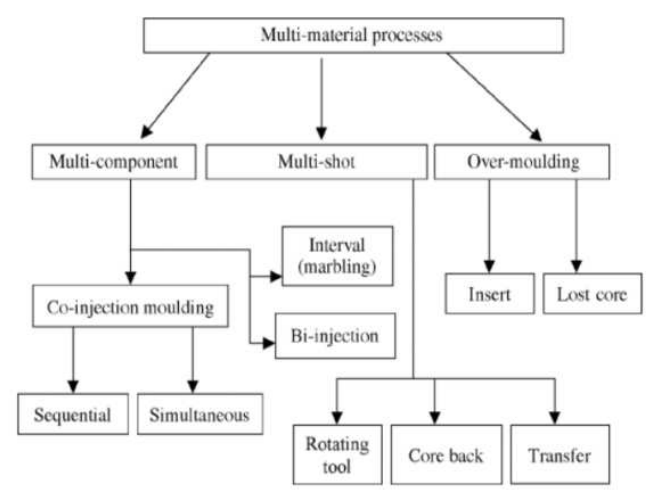

Figure 6 multi-material processes (Goodship \& Love 2002)

\section{PROTOTYPE TOOL FOR IN-MOULD ASSEMBLING}

The development of this new process followed a research path, which in this case was the definition of a case study, the optimization of the different processes, the construction of the manufacturing cell, and finally the production of the case study part. In figure 3 it is presented the $3 \mathrm{D}$ model of the case study part.

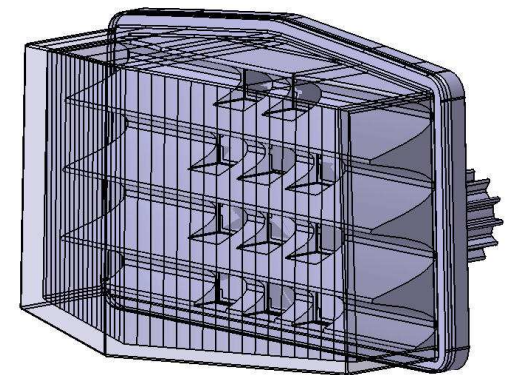

Figure 7 final rear lamp.

\subsection{Simulation of the injection moulding process}

The simulation of the process had the objective of understand if the injection moulding process can be used to produce the components and which defects can appear. The simulation was made with the Moldflow software. The first component to be analysed was the housing. To reduce the complexity of the mould, it was decided to inject the housing in one point. To simulate the filling phase was used a polycarbonate (PC) Lexan 123R as the raw-material. The simulation led to a fill time of $3 \mathrm{~s}$. Next it was analysed the volumetric shrinkage of the component, Figure 4.

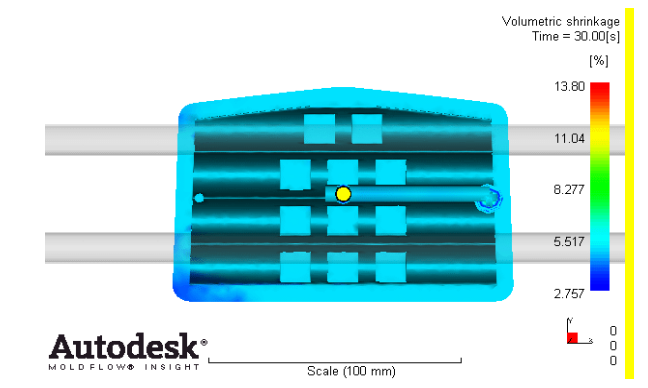

Figure 8 volumetric shrinkage of the housing

The housing presented a volumetric shrinkage of $5.5 \%$. The only exception appeared near the bottom of the left edge of the housing. In this zone it was seen a lower value of volumetric shrinkage. Considering the difference on the volumetric shrinkage between this zone and the remaining part, it is possible in the future to occur warpage. Despite this problem, the injection point was kept there, since the injection at the centre could create problems in the light propagation.

The fill phase of the transparent component (crystal) was also simulated, and a poly (methyl metacrylate) (PMMA) Plexiglas $8 \mathrm{~N}$ was used as rawmaterial. The location of the injection point was decided based on the requirements of the mould. The simulation suggested a fill time of $2.3 \mathrm{~s}$ to produce the part. The volumetric shrinkage was analysed. The simulation showed shrinkage of $0.429 \%$, as in Figure 8. This result indicates that the component will come out of the mould with no visible deformation. 


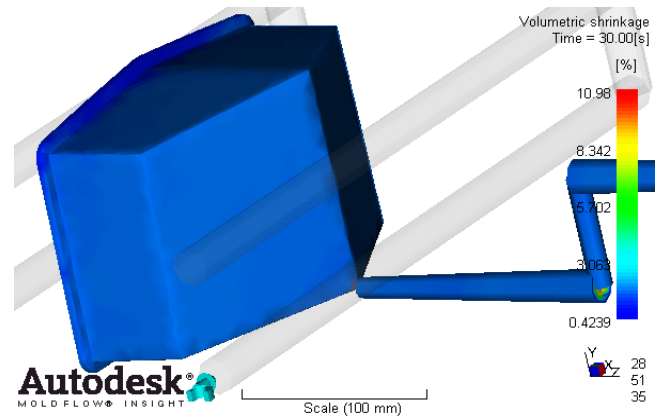

Figure 9 volumetric shrinkage of the crystal

\subsection{Mould concept}

In the development of the mould it was needed to define how the case study part will be produced, and understanding how it will be produced and assembled in a single mould. To accomplish this objective it was developed a mould with the capacity to:

- Produce at the same time the circuit, the housing and the crystal

- Assembly all components.

- Laser welding process

To accomplish the main objective it was designed a mould (Fig. 6) with an assembling system with two rotary plates with the capability to transport the different parts to be assembled and welded. The plates had also the capability to eject the final subsystem. In the mould it was created a system capable to maintain the two parts in contact during the weld process. This system consisted of a metallic ring.

The brown and blue plates (Fig. 6) are the rotary plates that control the process.
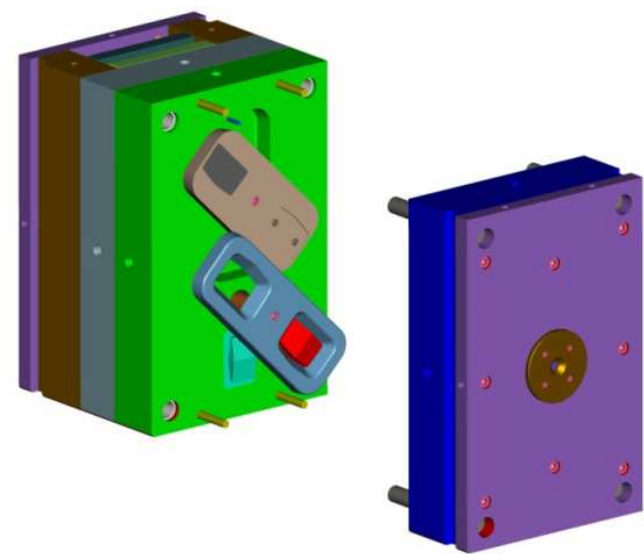

Figure 10 mould concept

\section{THE MANUFACTURING CELL}

The main objective of this project was the development of a manufacturing cell with the capability of producing in the same cycle a complete and functional case study. In the following Figure 7 they are presented the components used in the manufacturing cell.

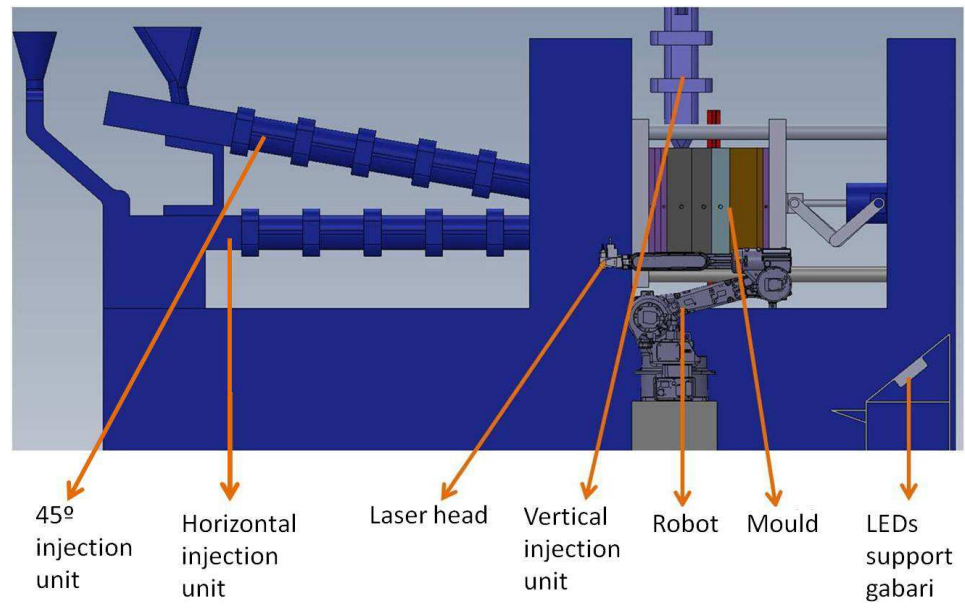

Figure 11 A 3D sketch of the manufacturing cell

In the injection moulding process it was used a bi-material injection moulding machine Billion Hercule H150/470-200T and a Plasdan ELM vertical unit. The vertical unit injected the electric circuit. The Billion Hercule was used to inject the housing ( $45^{\circ}$ injection unit) and the crystal (horizontal unit). The hydraulic system of the Billion Hercule was used to control the rotary plates of the mould since it already had a pre-installed software with that capability. The vertical unit was integrated with the Billion Hercule through specific software developed for this case. The temperature of the hot runners was controlled with a Mseries multizone controller. The temperature in the mould was controlled with a temperature control unit. Due to the specifications of the materials it was needed to use a drying/dehumidifying unit. The manufacturing cell was divided into two processes: the injection moulding and the laser welding process. To do the welding it was used an IA20 robot controlled by NX100 unit and a diode laser Laser LM100 (Mergenthaler Laser Technology), equipped with a pyrometer LH500. The laser head was connected to the robot through a system developed for this process. The use of the laser system implied the construction of an aluminium protection around the injection machine. The inte- 
gration of the two processes was made in the control unit of the robot.

\section{THE PROCESS TASKS}

To produce the case study in the same cycle, were needed several tasks:

1- The LEDs are added with the help of a robot into the cavity with the number 6 (Fig. 8);

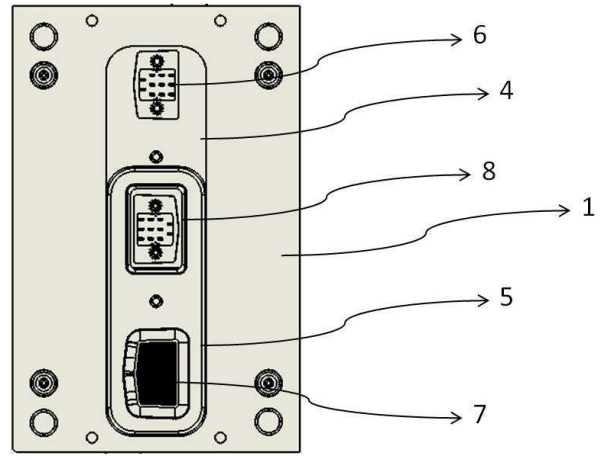

Figure 12 different sections of the mould used on the process

2- The mould closes;

3- The electric circuit, housing (with electric circuit) and the crystal are injected ;

4- The mould opens;

5- The plate 5 (Fig. 8) moves forward and rotates $180^{\circ}$. This movement transport the crystal to the assembling zone;

6- The plate retreats and assembles the crystal with the housing;

7- The laser welds the two parts;

8- The plates number 4 and 5 (Fig.8) move forward;

9- The number 4 plate rotates $180^{\circ}$ to the position indicted with the number 6 (Fig. 8);

10- The number 5 plate (Fig. 8) rotates to the initial position;

11- The two plates retreat and the subsystem is extracted;

12- The process restarts.

\section{RESULTS AND PROCESS VALIDATION}

Several challenges were found and solved in the implementation of this process.

In order to integrate all the operations in the same mould and to guarantee the quality of each component it was decided to study each component individually. After validating each component, the study of the complete process was initiated. The first setback to be solved was the ejection system of the crystal. During the ejection of crystal, several remained attached to the core. To overcome this problem it was created a texture in the metallic ring to improve the extraction (Figure 9).

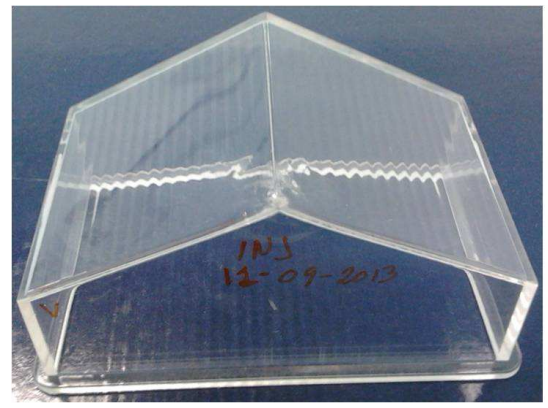

Figure 13 The crystal component

The housing (Fig. 10) was initially injected without the electric circuit. The housing presented a few voids at the bottom and in the reflection cavities. These defects were corrected with the integration of the electric circuit.

The last component to be studied was the electric circuit. The circuit was initially produced with a masterbatch of PC with CNT. The use of this material demands high temperature. Due to this and the use of hot runners it was seen that the LED melted and the rubber shaped material at the end of the process. To overcome the problem it was decided to replace the PC by a PP with CNT. With this it was possible to produce an operational electric circuit.

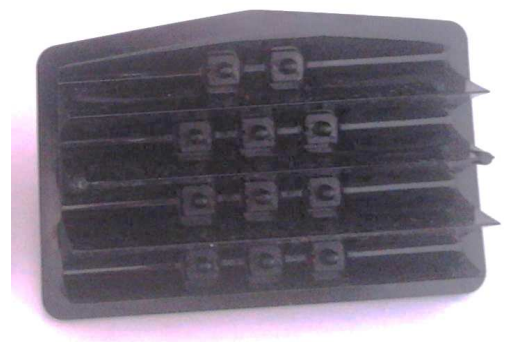

Figure 14 The housing with the electric circuit

The overmould (housing with the electric circuit) was analysed at the microscopic level in the union regions.

The analysis was done with a Meiji Techno EMZ-TR microscope and an Optika TB 3.0 with an augmentation of $0.5 \times$. The results showed a perfect contact between the two materials. However in the pin zone (yellow box) it was seen an overlap (Fig. 11).

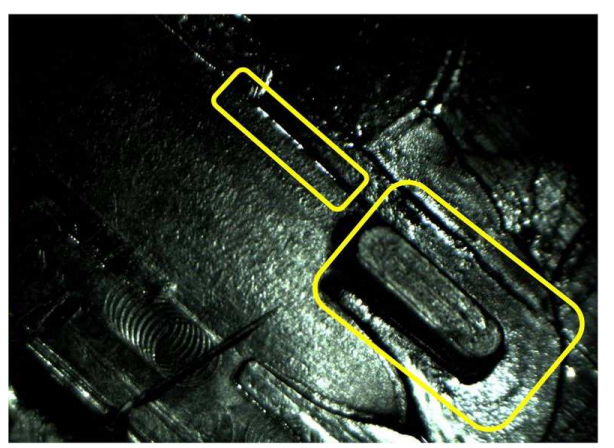

Figure 15 interaction between the PC and PP 
The last process to be studied was the laser welding of the housing with the crystal. The welding process occurred as expected. The final case study product is presented in the Figure 12.

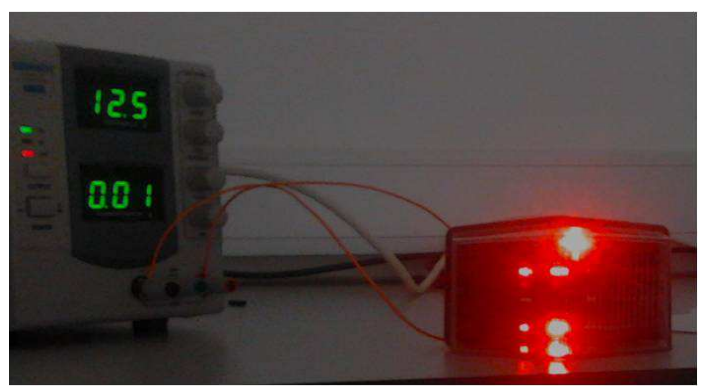

Figure 16 Final rear lamp

\section{CONCLUDING REMARKS}

The process presented in this study had the objective of reducing the time and the complexity of the current production cycle. To achieve this objective it was chosen a case study product. To achieve the objective it was needed to do several modifications to the original part design and it was needed to add equipment and systems to the process.

During the study several setbacks appeared as the higher temperature measure inside of the electric circuit cavity. To overcome the problem it was decided to change the material. The final setback that appeared was the extraction system that needed to suffer a few modifications during the study.

The overmoulding component was analysed at the microscopic level. The analysis showed a perfect contact between the two materials.

The laser welding between the housing and the crystal was achieved as planned.

At the end it is possible to conclude that this manufacturing cell is a viable production seup.

\section{REFERENCES}

Cunha, A. M., Pontes, A.J. 2009. Non-conventional injection molds. In Injection molding: Fundamentals and application, Chapter 4. M. R. Kamal, A. Isayev, and S.-H. Liu (eds), Hanser publishers, Munich, 21 Chapters, p. 926,

Feenstra, R. C. Autumn, 1998. Integration of Trade and Disintegration of Production in the Global Economy. The Journal of Economic Perspectives. 12. 4: 31-50

Goodship, V.; Love, J.C. 2002. Multi-Material Injection Moulding. Rapra Technology Limited, Volume 13, Number 1

Troughton, M. 2008. Handbook of Plastics Joining: A Practical Guide. William Andrew Inc.: 78-93. 